\title{
Hydroxychloroquine, TTP, COVID-19, and SLE
}

Hidroksiklorokin, TTP, COVID-19 ve SLE

\author{
(D) Pathum Sookaromdee1, (D) Viroj Wiwanitkit2 \\ 1 Private Academic Consultant, Bangkok, Thailand \\ ${ }^{2}$ Adjunct Professor, Joseph Ayobabalola University, Ikeji-Arakeji, Nigeria
}

\section{To the Editor,}

The recent report entitled "Hydroxychloroquine-associated thrombotic thrombocytopenic purpura" (TTP) was very interesting [1]. Arıkan et al. [1] concluded that the patient represented a possible case of hydroxychloroquine-induced TTP and called for awareness of this possible adverse effect of hydroxychloroquine $(\mathrm{HO})$ in alternative therapy for coronavirus disease-19 (COVID-19). In fact, TTP might be the result of many disorders. In the present case, it can be confirmed that the patient had TP, but the etiology is not clear. There is a lack of explanation of the patient's presenting symptom. The exact disease of the patient at the first presentation is a question to be discussed.

First, hydroxychloroquine-related TP is extremely rare and the dosage should be high. In this patient, the dosage might not have been high. Also, there are many criteria of the Naranjo scale that might not have been completely fulfilled, such as proven drug existence in the blood, history of previous reaction, reappearance after re-administration, worsening after increasing dose, improvement after discontinuation, and exclusion of other possible objective evidence. Second, whether this was COVID-19 or not has to be discussed. It is clear that there was a negative polymerase chain reaction (PCR) result. It is possible that this patient might have had a clinical presentation resembling a COVID-19 case such that the physician in charge decided to use $\mathrm{H}$ alternative therapy without waiting for the PCR test for COVID-19. Regarding negative PCR results, there is a chance of a false negative. In a recent publication, Arevalo-Rodriguez et al. [2] stressed "the need for repeated testing in patients with suspicion of SARSCoV-2 infection given that up to 54\% of COVID-19 patients may have an initial false-negative reverse transcription polymerase chain reaction." To decrease the false negative rate, it was suggested to consider the evidence of abnormal blood aspartate aminotransferase and lactate dehydrogenase level [3], which were also observed in the present case. Additionally, TTP might also be induced by COVID-19 [4].

Third, if we believe that this was not a COVID-19 case, it should be further considered what illness the patient had. Another possibility that might be easily forgotten is systemic lupus erythematosus (SLE). The patient had many clinical features, such as hematological findings, that might be seen in SLE. Nevertheless, there was a lack of complete laboratory work-up for SLE; therefore, that diagnosis was not possible. In SLE, TP might be the clinical presentation [5]. The use of steroids as well as plasmapheresis can also help treat patients with SLE-related TाP.

Keywords: Hydroxychloroquine, TTP, COVID-19, SLE

Anahtar Sözcükler: Hidroksiklorokin, TTP, COVID-19, SLE

\section{Ethics}

Informed Consent: Not applicable.

\section{Authorship Contributions}

Concept: P.S., V.W.; Design: P.S., V.W.; Data Collection or Processing: P.S., V.W.; Analysis or Interpretation: P.S., V.W.; Literature Search: P.S., V.W.; Writing: P.S., V.W.

Conflict of Interest: No conflict of interest was declared by the authors.

Financial Disclosure: The authors declared that this study received no financial support.

\section{References}

1. Arıkan F, Yıldız Y, Ercan T, Oruç O, Akçay S, Yılmaz F, Toptaş T, Tuğlular T. Hydroxychloroquine-associated thrombotic thrombocytopenic purpura. Turk J Hematol 2020;37:302-304.

2. Arevalo-Rodriguez I, Buitrago-Garcia D, Simancas-Racines D, ZambranoAchig P, Del Campo R, Ciapponi A, Sued 0, Martinez-Garcia L, Rutjes AW, Low N, Bossuyt PM, Perez-Molina JA, Zamora J. False-negative results of initial RT-PCR assays for COVID-19: a systematic review. PLoS One 2020;15:e0242958.

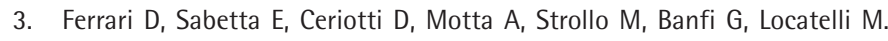
Routine blood analysis greatly reduces the false-negative rate of RT-PCR testing for COVID-19. Acta Biomed 2020;91:e2020003.

4. Altowyan E, Alnujeidi 0, Alhujilan A, Alkathlan M. COVID-19 presenting as thrombotic thrombocytopenic purpura (TTP). BMJ Case Rep 2020;13:e238026.

5. Bamidele OF, Akintayo RO, Bojuwoye MO, Alabi TO, Akintayo FC, Bamidele OV. Thrombotic thrombocytopenic purpura as the first presentation in systemic lupus erythematosus. Reumatologia 2018;56:268-270. 


\section{To the Editor,}

We thank our colleagues for their valuable comments and interest in our recently published letter [1]. Thrombotic thrombocytopenic purpura (TP) is a life-threatening thrombotic microangiopathy. Most patients present with a pentad of symptoms. However, only less than $10 \%$ experience all elements of the identified criteria. Most of the symptoms related to TРP are caused by microthrombi [2]. It is quite possible to have patients who present with symptoms attributable to tissue/ organ ischemia. Thus, chest/back pain as the first presenting symptom of TP has been reported, and after exclusion of other life-threatening conditions, it should be considered as a diseaserelated symptom as well $[3,4]$. We did not mention that this symptom is regarded as a presenting symptom of TTP, since the manuscript length is restricted for letters. The patient had two negative polymerase chain reaction (PCR) results for COVID-19 and chest computed tomography (CT) with angiography did not reveal pulmonary thromboembolism. Cardiac markers were not consistent with acute coronary syndrome. Chest/back pain was relieved by plasma exchange therapy. Thus, the first presenting symptom of the patient was clearly related to TTP.

We presented the whole Naranjo scale and calculated an overall score, according to which we declared that a relationship between hydroxychloroquine ( $\mathrm{HO}$ ) and TP was possible. We did not claim that all Naranjo criteria were fulfilled. Moreover, there is no need to have a full Naranjo score to draw a causal relationship.

COVID-19 has persisted for about a year or so. Information about the clinical symptoms, diagnosis, and definite treatment is still scarce. Almost all treatment options initially accepted as the gold standard have been substantially changed by the results of randomized controlled trials. Thus, all we could do was perform PCR and thorax CT to make a diagnosis. We did so, and we had negative results twice. What more could have we done to exclude the possibility of COVID-19? Further discussion would be mere speculation. However, people do die because of the catastrophic course of this disease, and we think that COVID-19 leading to TP would have followed a more catastrophic clinical course than that experienced by our patient.

Finally, most cases of TTP are idiopathic. In our case, however, we have claimed a possible relationship between $\mathrm{HO}$ and TTP. Systemic lupus erythematosus can be an underlying disease of TТ. However, it is mostly seen in women of child-bearing age; it is extremely rare in 65-year-old men.

Best Regards,

Fatma Arıkan, Yasin Yıldız, Tarık Ercan, Özen Oruç, Seçkin Akçay, Fergun Yılmaz, Tayfur Toptaş, Tülin Tuğlular

\section{References}

1. Arıkan $F_{1}$, ııldız $Y$, Ercan T, Oruç 0 , Akçay $S$, Yılmaz F, Toptaş $T$, Tuğlular T. Hydroxychloroquine-associated thrombotic thrombocytopenic purpura. Turk J Hematol 2020;37:302-304.

2. Joly BS, Coppo P, Veyradier A. An update on pathogenesis and diagnosis of thrombotic thrombocytopenic purpura. Expert Rev Hematol 2019;12:383395.

3. Griffin D, Al-Nouri ZL, Muthurajah D, Ross JR, Ballard RB, Terrell DR, Vesely SK, George JN, Marques MB. First symptoms in patients with thrombotic thrombocytopenic purpura: what are they and when do they occur? Transfusion 2013;53:235-237.

4. Wiernek SL, Jiang B, Gustafson GM, Dai X. Cardiac implications of thrombotic thrombocytopenic purpura. World J Cardiol 2018;10:254-266. 